depth of $80 \mathrm{~km}$., and thereafter a fairly steady density-gradient down to a depth of $2,700 \mathrm{~km}$. The gradient increases sharply in the next $200 \mathrm{~km}$., the density attaining $5.57 \mathrm{gm} . / \mathrm{cm}^{3}$ at the base of the mantle, while inside the central core it ranges from 9.74 to $12 \mathrm{gm} . / \mathrm{cm} .{ }^{3}$ at a depth of $4,980 \mathrm{~km}$., and then rises sharply to a value of $17-18 \mathrm{gm} . / \mathrm{cm}^{3}$ at the centre. In Bullen's more recent paper it is shown that, assuming Venus and the earth are of the same primitive composition, it is probable that Venus also contains an inner core. The earth's inner core, as Bullen has previously pointed out, is chemically distinct from the rest of the earth, and the same is believed to apply to Venus and Mars also, the evidence being based on the mass and radius of Mars, the figure of Mars, and the mass and radius of Venus, assuming that the model mentioned at the beginning of the paper fits the earth. The ellipticity $e$ of Venus can be derived from the formula $e=(1.68 \pm 0.07) 10^{-6} y^{-2}$, if the period of rotation of Venus is $20 y$ days. This formula, however, can be significant only if $y$ is much less than unity, and present indications of the rotation period of Venus do not suggest this as being very probable. On the other hand, if $y$ is of the order of unity, the value of $e$ would not be resolvable by direct observation, and in any case would be dwarfed by surface inequalities sustained by the strength of Venus. For these reasons, little help can be derived from observations of the figure of Venus at present.

Parliamentary and Scientific Committee: Annual Report

THE activities of the Parliamentary and Scientific Committee (31 Palace Street, London, S.W.I) have for the most part been noticed in Nature as they occurred; but the annual report recently issued also includes the text of a letter from the Minister of Education commenting on the Committee's report on technical education and indicating his readiness to receive a deputation. The Minister observes that he fully recognizes the importance of craft training and the need to combine organized practical training in the works with technical education in the colleges. While the Ministry is encouraging voluntary day release and the provision of more practical courses leading to qualifications of the City and Guilds of London Institute, and the Minister shares the Committee's view as to the expansion of sccondary technical schools, he doubts whether such schools are appropriate for technical education. Detailed surveys of industrial needs have already been made by most of the local authorities in preparing their Schemes of Further Education and plans for county colleges. The Ministry is doing its best to improve accommodation and equipment, and some $£ 50$ millions of new buildings were begun in the last year, the highest priority being now given to workshop and laboratory accommodation. Afterwards, on November 22, 1950, a deputation from the Committee discussed in detail with the Minister the implementation of these and other recommendations on which the Minister had commented. The report also includes the text of a letter from the Committee's chairman, Mr. Philips Price, to The Times (November 24, 1950) urging further effort to secure greater efficiency in the field of coal utilization, and an adequate investment for the installation both in factories and houses of the most efficient coal-burning and coal-using equipment that science and technology can devise, as well as the intensification of research in this field.

\section{Division of Chemical Physics of the American Physical Society}

The Council of the American Physical Society, as requested in a recent issue of Physics Today, has revived the idea of establishing a Division of Chemical Physics, and a committee consisting of Dr. F. G. Brickwedde, Prof. J. G. Kirkwood, Dr. J. E. Mayer, Prof. H. H. Nielsen and Prof. O. K. Rice, with Prof. R. S. Mulliken as chairman, has drawn up a draft set of by-laws. The principal objective of the new Division is stated to be "the advancement of understanding in subjects of chemical interest whose development depends strongly on modern physical theories or techniques". Membership of the new Division is open to all members and fellows of the American Physical Society on application. An entrance fee is payable, but no annual subscription. It is hoped to inaugurate the Division at the meeting of the Society in Pittsburgh during March 8-10, which will comprise a symposium on molecular structure and valence theory and on topics involving statistical mechanics. This will be followed in June by a symposium on molecular structure and spectroscopy.

\section{Society of Plant Morphologists}

DURING the recent annual session of the Indian Science Congress, held at the Indian Institute of Science, Bangalore, a large group of Indian botanists interested in plant morphology met on January 4 and decided to form a Society of Plant Morphologists. It was resolved that the Society should start a Journal devoted to all aspects of plant morphology from Algæ. to Angiosperms and run it on an international basis. Pending formal election of office bearers some time next year, it has been arranged that Prof. P. Maheshwari, head of the Department of Botany, University of Delhi, Delhi 8, should act as convener of the Society and editor of the Journal. Inquiries relating to the Society and all subscriptions should be sent to Prof. Maheshwari. The annual membership fee is $£ 2$ for botanists residing outside India. For non-members the subscription to the Journal is $£ 25 s$.

\section{National Capital Wealth of Great Britain}

In the annual report for $1949-50$ of the National Institute of Economic and Social Research (pp. 32 ; from 2 Dean Trench Street, London, S.W.1), the approaching completion of a stage in the work of the Institute is announced, and its future plans are briefly explained. Hitherto, a large part of its resources have been devoted to the study of the national income of the United Kingdom and the establishment of the basic statistics in this field. The Institute now proposes to undertake a number of studies in the field of capital, of which the first will be a critical appraisal of historical estimates of the national capital, the concepts used, and the statistical methods and sources employed. Very little work, it is pointed out, has been done during the past fifteen years on the national capital, despite the greatly increased interest in the study of the national income, and despite the fact that in the nineteenth and the early years of the twentieth centuries frequent attempts were made to estimate the national capital. If feasible, these earlier estimates will be recalculated on a more uniform basis, and an attempt will also be made to link up estimates of the magnitude and composition of the national wealth with annual estimates of capital (or asset) formation. It is believed that it 